\title{
Ultra-Wideband Antenna with Y-Shape Defected Ground Structure
}

\author{
Mohamad Harris Misran', Maizatul Alice Meor Said ${ }^{2}$, Azahari Salleh $^{3}$, Ridza Azri Ramlee ${ }^{4}$ \\ ${ }^{1,2,3,4}$ Centre for Telecommunication Research \& Innovation (CeTRI), Faculty of Electronics and Computer \\ Engineering, Universiti Teknikal Malaysia Melaka, Hang Tuah Jaya, 76100 Durian Tunggal, Melaka, Malaysia \\ Email: ${ }^{1}$ harris@utem.edu.my, ${ }^{2}$ maizatul@utem.edu.my, ${ }^{3}$ azahari@utem.edu.my, ${ }^{4}$ ridza@utem.edu.my
}

\begin{abstract}
Ultra-Wide Band (UWB) technology is rapidly developing area in the field of wireless communication. There are many challenges in this field; one of the challenges is to design an antenna that covers the entire UWB frequency range. The paper present the design UWB antennas that operates in the frequency range from $3 \mathrm{GHz}$ to $12 \mathrm{GHz}$. Rectangular microstrip planar patch antenna integrated with Defected Ground Structured, which is Y-shaped, and full ground plane is proposed. The antenna is simulated using CST Microwave Studio software. A comparative parametric analysis has been made based on return loss, gain, radiation pattern characteristic and impedance bandwidth. The antenna is fabricated, measured and verified using vector network analyzer and good agreement was observed. DGS implementation is able to improve the antenna bandwidth significantly from $0.5 \mathrm{GHz}$ to $8.9 \mathrm{GHz}$. The antenna is able to operate at UWB which is covered $3.1 \mathrm{GHz}$ to $12 \mathrm{GHz}$ with gain of $4.1 \mathrm{~dB}$. Proposed antenna present good candidate for UWB applications due to their special characteristic such small size, low profile, low cost, wide bandwidth and almost omnidirectional radiation pattern.
\end{abstract}

Key words : Ultra-wide band (UWB), Defected Ground Structure (DGS)

\section{INTRODUCTION}

Wireless technology for communication purposes offers cheaper equipment and adaptable way. In communication systems, antenna has its significance; It delivers electromagnetic energy radiation in all directions evenly. Antenna is a transducer that transforms one energy form to another. Its role electromagnetic waves are transmitted or received from one source to the destination. Microstrip antennas have a few benefits compared to other standard microwave antennas and are thus widely used in many commercial applications. Almost all microstrip patches were produced for use in wireless applications [1].

Special attention is given to Ultra-wideband (UWB) nowadays in industry also academia. This technology is being used over the previous 20 years in the fields of sensing, radar and military communications. This system offers a great instant bandwidth and the potential for quite simple application. In addition, the broad bandwidth and great promise low-cost digital design make it possible for a single device to operate as a communication device, radar or locator in different ways [2]. After the Federal Communications Committee's consent in 2002, a great deal of research has been conducted on UWB technology, especially for wireless communications [3]. For the unauthorized use of UWB equipment in the 3.1- to $10.6-\mathrm{GHz}$ frequency band, the FCC provided $7500 \mathrm{MHz}$ spectrum and described a radio system as an UWB if a spectrum of more than 20 percent of the central frequency bandwidth is used [4].

The demand has increased over the years of large capacity of data and high-speed data transmission rate [5]. To meet the requirement of large capacity of data rate, width bandwidth is compulsory for wireless communication system.. In addition, there is often a need for small size and compact profile antennas, broadband antennas, to cover multiple bands at once [6]. As a high data rate wireless communication technology, UWB is progressing quickly. Large bandwidth is obtained by designed a slot UWB antenna so that large capacity of data and high-speed data transmission rate is achieved.

The patch antenna usually has a spurious frequency and defected ground structure (DGS) is created on the ground plane of the transmission to overcome it. The DGS at the ground behaves as a low pass filter to decide the frequency which can be passed through the transmission line [7]. Research on the subject of DGS has become greatly concerned, Defected Ground Structure in recent years and in certain implementations, increased application ability have been demonstrated [8][9][10]. DGS systems have many benefits in filtration for circuits, like circuit reduction in size and deletion of false responses. Different kinds of DGS is used to meet the right application and compact filtering requirements [11][12][13]. spurious response of the microstrip low pass filter and coupled band-pass filter can be 
achieved by DGS implementation. DGS also has multiple used such as building block of the filter; they are rather viewed to improve the response of filters, couplers and oscillators [14].

To eliminate the false frequency, it is proposed to use Defected Ground Structure (DGS) for its ability of effectively suppressing this kind of frequency That is used in the patch antenna transmission line as it is easy to construct and fabricate [11][15].

The coaxial probe feeding is used because the feed can be placed at any desired location on the patch in order to match cable impedance with the antenna input impedance freely [16].

\section{DESIGN SPECIFICATION}

The structure and dimensions of the proposed antenna was optimized from previous design are given in Figure 1.
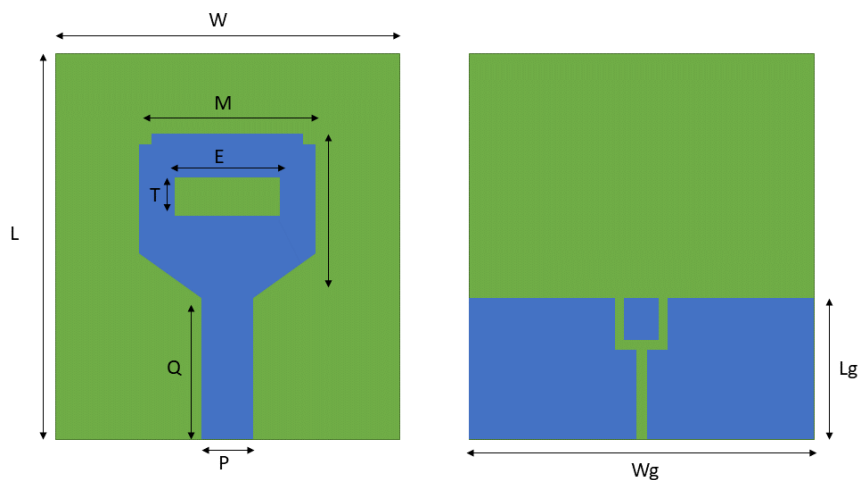

Figure 1: Patch Antenna and Ground plane

A $50 \Omega$ microstrip feed line is on top of FR4 substrate. Parameter of width (W), effective dielectric constant $\left(\varepsilon_{\mathrm{eff}}\right)$, effective length $\left(\mathrm{L}_{\mathrm{eff}}\right)$, length extension $(\Delta \mathrm{L})$ and actual length of the antenna patch were calculation using equations (1) (5) theoretically before optimization process was made.

$$
\begin{gathered}
W=\frac{c}{2 f_{\sigma} \sqrt{\frac{\left(\varepsilon_{r}+1\right)}{2}}} \\
\varepsilon_{e f f}=\frac{\varepsilon_{r}+1}{2}+\frac{\varepsilon_{r}-1}{2}\left[1+12 \frac{h}{W}\right]^{-\frac{1}{2}} \\
L_{e f f}=\frac{c}{2 f_{0} \sqrt{\varepsilon_{e f f}}} \\
\Delta L=0.412 h \frac{\left(\varepsilon_{e f f}+0.3\right)\left(\frac{W}{h}+0.264\right)}{\left(\varepsilon_{e f f}-0.258\right)\left(\frac{W}{h}+0.8\right)} \\
L=L_{e f f}-2 \Delta L
\end{gathered}
$$

The $f_{\sigma}, \mathrm{W}, \mathrm{L}, \mathrm{h}, \varepsilon$ and $\mathrm{c}$ refer to resonance frequency, width of the patch, length of the patch, the thickness, relative permittivity of the dielectric substrate and speed of light respectively. The substrate has a thickness, $\mathrm{h}=1.6 \mathrm{~mm}$ and a relative permittivity $\varepsilon \mathrm{r}=4.4, \mathrm{Ls}=29 \mathrm{~mm}$ and $\mathrm{Ws}=28 \mathrm{~mm}$ denoting the length and width of the substrate, respectively. Meanwhile PEC has a thickness of $0.036 \mathrm{~mm}$. Table 1 shows the parameter of proposed antenna.

Table 1: Parameter of Antenna

\begin{tabular}{|c|c|}
\hline Parameter & Value (mm) \\
\hline W & 28 \\
\hline M & 14 \\
\hline E & 6 \\
\hline T & 1.5 \\
\hline L & 29 \\
\hline Q & 12 \\
\hline P & 3.5 \\
\hline Wg & 28 \\
\hline Lg & 10.5 \\
\hline
\end{tabular}

The patch, feed line on the top of the substrate, mean while the Defected Ground Structure is on ground plane at the back. A Y-shaped slot was etched from the half ground plane with $3 \mathrm{~mm}$ width.

\section{RESULTS}

The most important features to fulfill for the UWB antenna is the wide band bandwidth. The antenna bandwidth can be considered as the frequency range denoted by a return loss of less than $-10 \mathrm{~dB}$ and can be determined from the plot of return loss, $\mathrm{S}_{11}$.

\subsection{Simulation Results}

Figure 2 indicates that the bandwidth covers an incredibly broad frequency starting range from $3.1 \mathrm{GHz}$ to $12 \mathrm{GHz}$ with a resonant frequency of the antenna is $9.64 \mathrm{GHz}$ and the return loss is $-32 \mathrm{~dB}$ due to better impedance over frequency range.

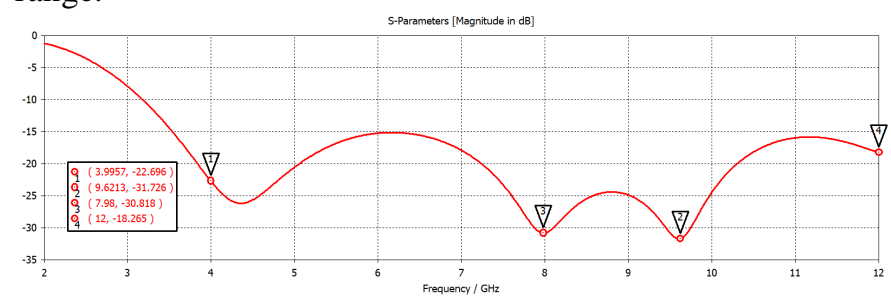

Figure 2: Return Loss of Antenna 
Based on the Figure 2, there is three resonant frequency (Fr) on the S-paramaters result. First Fr is at frequency $4.3 \mathrm{GHz}$ that has return loss $-24 \mathrm{~dB}$. Second Fr is at frequency 7.9 GHz, return loss equal to $-31 \mathrm{~dB}$ and the third resonant frequency is at frequency $9.7 \mathrm{GHz}$ that has a higher return loss among the rest which is $-33 \mathrm{~dB}$.

The gain for UWB antenna as shown in Figure 3 is $3 \mathrm{~dB}$ at frequency $8 \mathrm{GHz}$ and increasing until frequency $10 \mathrm{GHz}$

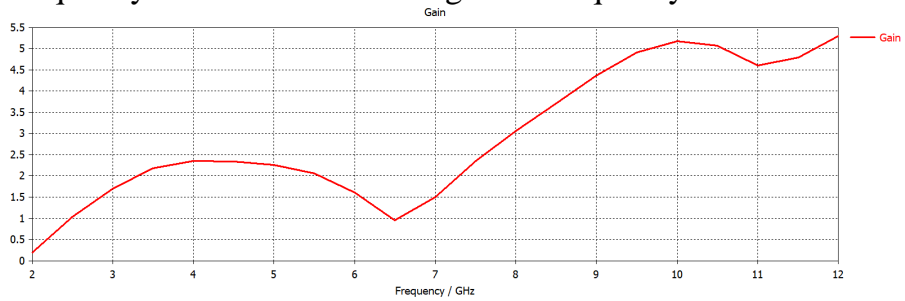

Figure 3: Gain of the Antenna

Figure 4 illustrate the simulated of radiation pattern for broadband in term of E-plane pattern. E plane is presented by $\mathrm{x}-\mathrm{z}$ plan, elevation plane.

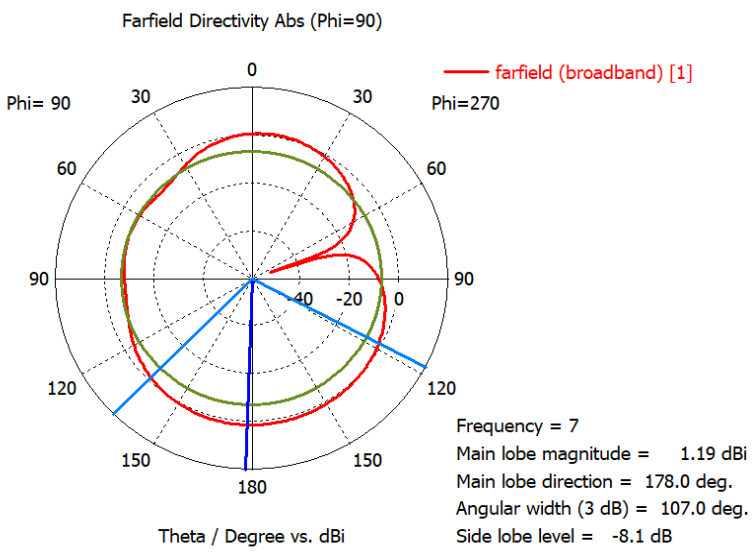

Figure 4: Radiation Pattern

The radiation pattern of the antenna shown in figure above plotted nearly as omnidirectional shape. In UWB application, the most suitable radiation pattern is omnidirectional shape to work more efficiently in data transmission field.

Figure 5 plot a voltage standing wave ratio (VSWR) of the microstrip antenna. The VSWR for patch antenna is always less than 2V. From Figure 5, it can be concluded that VSWR antenna is less than 2 over frequency. It affects the reflection coefficient that has been minimized by good impedance matching.

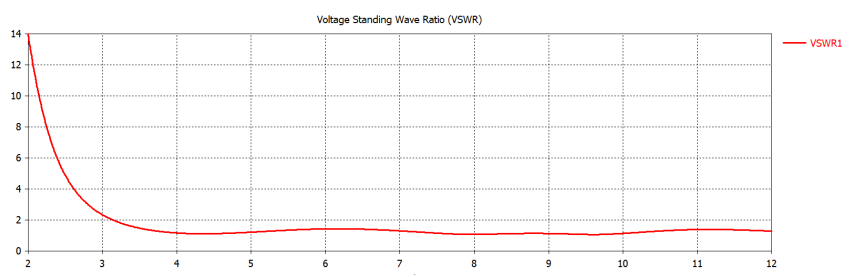

Figure 5: VSWR of the Antena

\subsection{Comparison Between With and Without DGS}

In order to prove the defected ground structure (DGS) method can improvised the impedance bandwidth, radiation pattern, return loss and gain of an antenna. Figure 6 shown the simulation result of return loss for both type of ground plane. For full ground plane, the operating frequency is only 9.4 to 9.9 GHz. Meanwhile, ground with DGS operating frequency is 3.1 to $12 \mathrm{GHz}$. Based on simulation, the DGS can increase the range of impedance bandwidth.

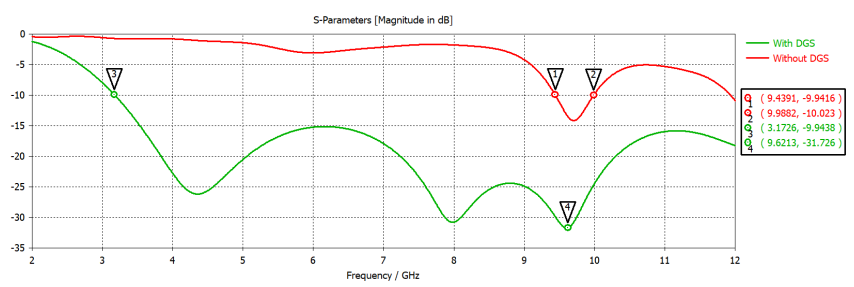

Figure 6: Return Loss

Table 2 shows comparison between two types of ground plane. Based on the table, the return loss of antenna with DGS is higher than the ground plane without DGS.

Table 2: Comparison both Results

\begin{tabular}{|c|c|c|}
\hline Parameter & Without DGS & With DGS \\
\hline Frequency range $(\mathrm{GHz})$ & 9.4 to 9.9 & 3.1 to 12 \\
\hline Resonant frequency $(\mathrm{GHz})$ & 9.7 & 9.6 \\
\hline Return loss, $\mathrm{S}_{11}(\mathrm{~dB})$ & -14.19 & -31.74 \\
\hline Gain $(\mathrm{dB})$ & 4.3 & 4.4 \\
\hline
\end{tabular}

Table 2 verify the effect of the DGS in designing patch antenna. The DGS act as filter that can reducing unwanted responses and resulting the wider bandwidth.

\subsection{Prototype Antenna}

The selection of a substrate for a microstrip patch antenna is very crucial in designing process. A good antenna will not be designed without proper selection of the parameter of the substrate such as length, width, height and dielectric constant [5]. Here FR4 substrate $1.6 \mathrm{~mm}$ of thickness and relative permittivity of 4.4 is used.

The antenna fabricated by using copper sheet as patch. To strip or remove unwanted copper in order to archive desired structure of the antenna, the FR4 has undergo etching process technique. For preparation on etching process, the substrate (FR4) and printed plastic film together through UV process to ensure the patch and ground structure shape is developed completely. 


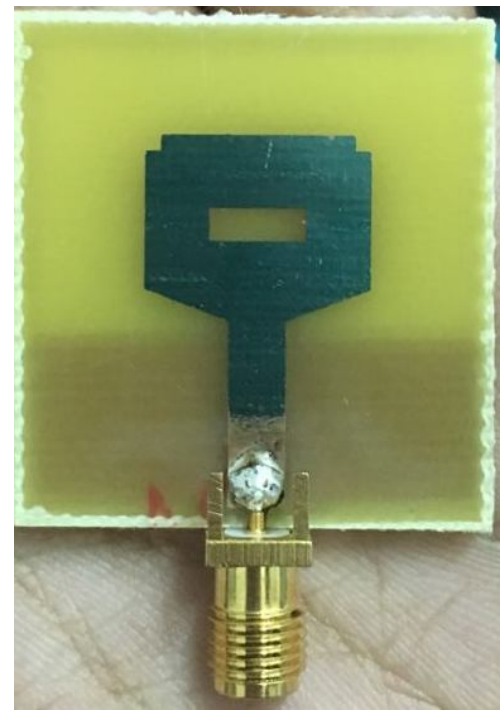

Figure 7: Front View of the Antenna

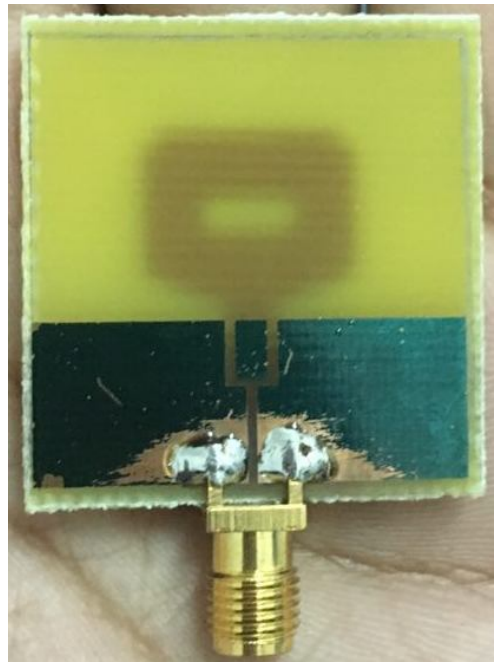

Figure 8: Back View of the Antenna

Lastly, SMA port is soldered to the patch antenna to connect them firmly together. The result of fabrication process is shown in Figure 7 and Figure 8.

\subsection{Measurement Results}

To justify how much transmitted signal is being reflects to the source, the fabricated antenna was measured by using vector network analyzer (Agilent).

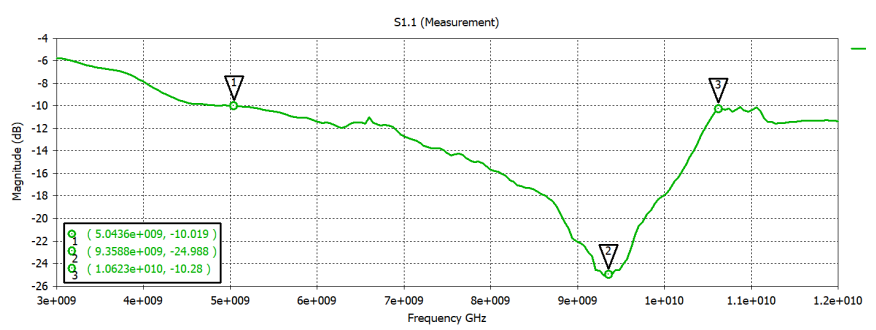

Figure 9: Return Loss, $\mathrm{S}_{11}$
Figure 9 shows the measurement result for return loss and impedance bandwidth of the antenna. The antenna was fabricated using standard etching technique that offer in faculty's lab. The measurement result was plotted by using CST software to get more understanding how the performance of the proposed antenna in the real life. The graph visualize that the antenna best performance is at 9.3 $\mathrm{GHz}$ because of its higher return loss among the others frequency which is $-25 \mathrm{~dB}$. Meanwhile for the accepting operating frequency is $5.07 \mathrm{GHz}$ to $12 \mathrm{GHz}$, giving the total bandwidth $7 \mathrm{GHz}$. Based on the result, the proposed antenna is still acceptable for UWB application.

The radiation pattern has taken the measurement in the anechoic chamber. The antenna was rotated using the horn antenna that capable to receiving data until $12 \mathrm{GHz}$ as test antenna positioning system. Based on measurement result shown on Figure 10, the fabricated antenna radiated at specific direction. The main lobe containing the maximum radiation. Meanwhile the back lobe and side lobes defined as the undesired directions.
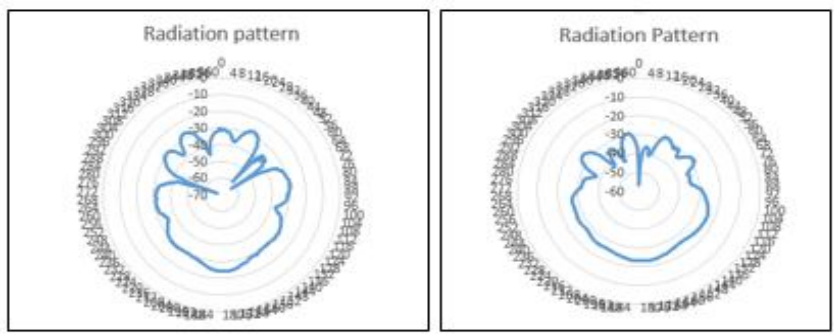

Figure 10: Radiation Pattern

\subsection{Comparison Between Simulation And Measurement Results}

The return loss of both simulation and measurement result is plotted in the same graph as shown in Figure 11. Based on Table 3 the return loss for measurement less than simulation result. The resonant frequency for simulation slightly same with measurement value. Meanwhile for gain, the value of measurement less than simulation results due to surrounding error.

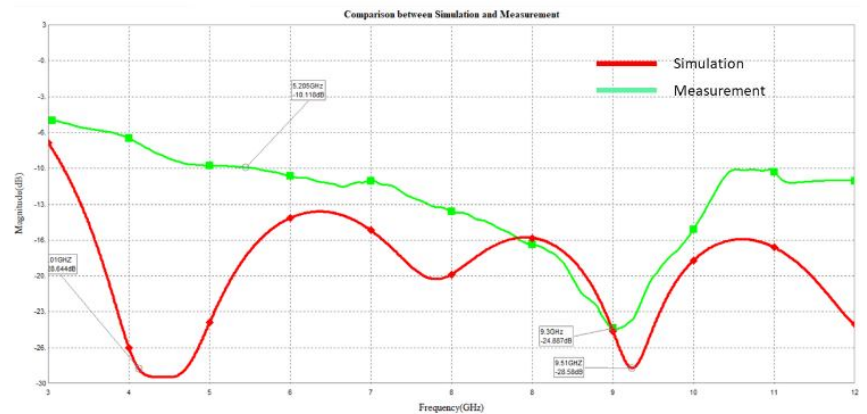

Figure 11: Comparison of Return Loss 
Based on the plotted graph above, the curve of the operating frequency for measurement result is slightly shifted to the right. However, the results for measurement are acceptable since the bandwidth nearly similar to the simulation results.

Table 3: Comparison both Results

\begin{tabular}{|c|c|c|}
\hline Parameter & Simulation & Measurement \\
\hline Frequency range $(\mathrm{GHz})$ & 3.1 to 12 & 5.6 to 12 \\
\hline Resonant frequency $(\mathrm{GHz})$ & 9.6 & 9.3 \\
\hline Return loss, $\mathrm{S}_{11}(\mathrm{~dB})$ & -31.74 & -25.02 \\
\hline Gain $(\mathrm{dB})$ at $9 \mathrm{GHz}$ & 4.4 & 4.1 \\
\hline
\end{tabular}

Based on the Table 3, the antenna performance in lab measurement is slightly different from the simulation. For operating frequency, range in simulation was achieved 3.1 $\mathrm{GHz}$ to $12 \mathrm{GHz}$ which is mean align with the project's objective. Meanwhile for measurement result shows that $89 \%$ similarity as simulation, the $11 \%$ was contribute by the error such as faulty in etching process or poor soldering technique.

\section{DISCUSSION}

The development and modeling of the project is focused primarily on the Ultra-Wideband application antenna with the rectangular microstrip patch. Comparisons of CST simulation results and measurement results by using VNA devices and anechoic chamber gave the better understanding into the effect on the antenna parameters of the manufacturing process. The value differences are very clear and can be determined from the comparison of the return loss parameter (simulation and measurement). Comparing between the simulation and measurement results, it is observable that there is an approximate of $10 \%$ of differences on the S-Parameters of the antenna. As for the operating frequency and impedance bandwidth can concluded that the simulation result gave the best results compared to measurement results which contains error that can affect the result such as etching process or poor soldering technique.

The unexpected error can be reduced or minimize by practice the right technique on physical works such as fabrication and cutting process. The material also gave effects on the simulation; in this case, the selection of substrate must be right. The FR-4 that provided from laboratory thickness and dielectric constant is slightly different from the one used in simulation.

\section{CONCLUSION}

The simulation and measurement results show promising results in term of enhancement impedance bandwidth by using defected ground structure technique, which consists on introducing Y-shape slot on the ground. This proposed technique is very simple to introduce in practice for UWB applications.

The first antenna is designed with full structure of ground same as substrate dimension. The second antenna with slots and new short ground plane was proposed. A Y-shape slot at the center of the ground plane are used to enhance the impedance bandwidth of antenna. The patch of the antenna is same in both first and second antenna without any change in the parameters.

Simulation result show that the operating bandwidth of the proposed antenna, after introducing the DGS, increases from 9.4 GHz to $9.9 \mathrm{GHz}$ (bandwidth of 0.5 ) to $3.1 \mathrm{GHz}$ to $12 \mathrm{GHz}$ (bandwidth of $8.9 \mathrm{GHz}$ ). It is observed that the performances of the modified antenna are better compared to the first antenna. The other parameter of antenna like impedance matching, radiation pattern and VSWR are given.

\section{ACKNOWLEDGEMENT}

The authors would like to acknowledge the Centre for Research and Innovation Management (CRIM) and Universiti Teknikal Malaysia Melaka for financing this project.

\section{REFERENCES}

1. Y. K. Gupta, R. L. Yadava, and R. K. Yadav, Performance Analysis of 2 . $3 \mathrm{GHz}$ Microstrip Square Antenna Using ADS, International Journal of Research in Management, Science \& Technology, vol. 1, no. 2, pp. 116-121, 2013.

2. R. Krishan and V. Laxmi, Design of Microstrip Antenna for Wireless Local Area Network, International Journal of Computer Science and Mobile Computing, vol. 4, no. 4, pp. 361-365, 2015.

3. L. Celis, et all, Ultra-Wideband : Past , Present and Future White Paper, EUWB European Commission, 10 October 2011.

4. A. a Kishk, Fundamentals of Antennas, Antennas Base Station Wireless Communication, January 2009, p. 1, 2009.

5. V. bankey and N. A. Kumar, Design and performance issues of Microstrip antennas, International Journal of Scientific and Engineering Research, vol. 6, no. 3, pp. 1572-1580, 2015. https://doi.org/10.14299/ijser.2015.03.008

6. R. Brenner et al., Development of Wireless Techniques in Data and Power Transmission Application for Particle Physics Detectors, 
Engineering, Physics, Computer Science ArXiv, pp. $1-20,2015$.

7. K. P. Yang et al., Ultra-Wideband Tapered Patch Antenna With Fractal Slots For Dual Notch Application, Microwave and Optical Technology Letters, vol. 56, no. 6, pp. 130-133, 2014.

8. F. Mohajeri et al., Antenna With Defected Ground, vol. 58, no. 12, pp. 2814-2818, 2016. https://doi.org/10.1002/mop.30151

9. R. A. Pandhare, P. L. Zade, and M. P. Abegaonkar, Harmonic Control by Defected Ground Structure on Microstrip Antenna Array, Indian Journal of Science and Technology, vol. 8, no. December, pp. 2-6, 2015.

10. Kalavala Vamsi Krishna et al., A Compact Rectangular Shaped Dipole Array Slot Microstrip Antenna with DGS for Multiband Applications, International Journal of Emerging Trends in Engineering Research, Volume 8. No. 2, pp. 408-413, February 2020 https://doi.org/10.30534/ijeter/2020/28822020

11. V. S. Melkeri, Microstrip Antenna with Defected Ground Structure : A Review, International Journal of Electrical Electronics and Telecommunication Engineering, vol. 46, no. 1, pp. 1492-1496, 2015.

12. G. P. Mishra and S. Modak, Performance Evaluation of Multi-functional Defected Ground Structure Embedded with Microstrip Patch Antenna for ISM Band Wireless Communications, International Conference on Communication, Networks and Computing, vol. 1. pp.64-75, Springer

13. Lakshmi Charan Tangisetti et al., A Compact UWB Microstrip Antenna With Hexagonal Circular Patch And Asymmetric CPW-Fed for On-body Applications, International Journal of Emerging Trends in Engineering Research, vol 8, no 2, pp.584-590, February 2020, $584-590$ https://doi.org/10.30534/ijeter/2020/49822020

14. F. S. Mahmud, M. S. Razalli, H. A. Rahim, W. F. Hoon, and M. Z. Ilyas, Parametric studies on effects of defected ground structure ( DGS ) for dual band bandstop microstrip filter, International Conference on Applied Photonics and Electronics 2017 (InCAPE2017), vol. 01063, pp. 10-14, 2017.

15. Aaron Don M. Africa et al., PCB/Microstrip Antenna Design and Simulation, International Journal of Emerging Trends in Engineering Research, Vol 7, No. 8, pp. 157-162, August 2019 https://doi.org/10.30534/ijeter/2019/09782019

16. S. M and S. S. Sibi Chakravarthy S, Sarveshwaran N, Comparative Study on Different Feeding Techniques of Rectangular Patch Antenna, Thirteenth International Conference on Wireless and Optical
Communications Networks (WOCN), vol. 3, no. 5, pp. $0-5,2016$.

https://doi.org/10.1109/WOCN.2016.7759032 